\title{
An Inverse Correlation Between Zn Stable Isotope Fractionation and Zn-O Bond Distances Revealed from Synchrotron-based X-ray Absorption Spectroscopy
}

\author{
WEI Li*, WeIQIANG Li, ZHAO WANG, WENXIAN GOU \\ School of Earth Sciences and Engineering, Nanjing \\ University, Nanjing 210023, China (*correspondence: \\ liwei isg@nju.edu.cn)
}

Sorption of $\mathrm{Zn}$ onto mineral surfaces can lead to notable $\mathrm{Zn}$ isotope fractionation, however, the fractionation mechanism remains poorly understood at the molecular scale. In this study, we demonstrate that $\mathrm{Zn}$ isotope fractionation $\left(\Delta^{66} \mathrm{Zn}_{\text {sorbed-aqueous }}\right)$ during $\mathrm{Zn}$ sorption onto $\mathrm{Al}$ oxide depends on the surface coverage $(\Gamma)$ and eventually on its bonding structure. At low $\mathrm{pH}(6.0-6.5)$ and/or low concentrations $(<0.4 \mathrm{mM})$, where $\Gamma<0.8 \mu \mathrm{mol} \mathrm{m}{ }^{-2}$, $\Delta^{66} \mathrm{Zn}_{\text {sorbed-aqueous }}$ is $0.47 \pm 0.03 \%$, whereas $\Delta^{66} \mathrm{Zn}_{\text {sorbed-aqueous }}$ decreases to $0.02 \pm 0.07 \%$ at $\mathrm{pH}$ 7.0-8.0 and large $\mathrm{Zn}$ concentrations $(\geq 0.4 \mathrm{mM})$, with a high $\Gamma>1.5 \mu \mathrm{mol} \mathrm{m} \mathrm{m}^{-2}$. Using extended X-ray absorption fine structure (EXAFS) spectroscopy, we elucidated that a $\mathrm{Zn}-\mathrm{Al}$ layered double hydroxide (LDH) with a $\mathrm{Zn}-\mathrm{O}$ bond length of $2.06 \AA$ forms at high surface coverage. In contrast, at low surface coverage, the sorbed $\mathrm{Zn}$ occurs as a tetrahedrally coordinated inner-sphere surface complex with an average $\mathrm{Zn}-\mathrm{O}$ interatomic distance of $1.98 \AA$, suggesting that shorter $\mathrm{Zn}-\mathrm{O}$ bond distance correlated to the large isotope fractionation .

We further experimentally determined the $\mathrm{Zn}$ isotopic fraction during its sorption onto mangnese oxides (todorokite and birnessite) and the corespinding $\mathrm{Zn}-\mathrm{O}$ distances. After summarizing these data with previsous studies on other mineral surfaces (e.g., quatze, goethite, ferrihydrite), we reveal that $\mathrm{Zn}$ stable isotope fractionation decrease from $0.92 \%$ to $-0.46 \%$ when $\mathrm{Zn}-\mathrm{O}$ distance increases from $1.92 \AA$ to $2.12 \AA$. This inverse correlation between isotopic fractionation, local bonding structures and solution chemistry would shed light on a fundmental understanding of metal stable isotope geochemitry. 